III Congresso Brasileiro de Informática na Educação (CBIE 2014)

XXV Simpósio Brasileiro de Informática na Educação (SBIE 2014)

\title{
Jogo Leis de Mendel - Ensinando genética de forma lúdica
}

\author{
Jakeline Soares de Lima1, Victor Afonso dos Santos ${ }^{1}$ \\ Universidade de Pernambuco, Campus Garanhuns (UPE) ${ }^{1}$ \\ CEP 55.294-902 - Garanhuns - PE - Brasil
}

\{jakelline29, victor.santosf92\}@gmail.com

\begin{abstract}
This paper presents the game laws of Mendel, educational software which aims to provide a fun and interactive learning of Mendelian genetics. The game has a pedagogical agent that will assist the user during the assimilation of concepts, these are presented in a fun and interactive way where users actively participate in all crosses made with peas.

Resumo: Este artigo apresenta o jogo Leis de Mendel, software educativo que tem como objetivo proporcionar um aprendizado lúdico e interativo da genética Mendeliana. $O$ jogo conta com um agente pedagógico que auxiliará o usuário durante a assimilação dos conceitos, estes são apresentados de forma lúdica e interativa, onde o usuário participará ativamente de todos os cruzamentos realizados com as ervilhas.
\end{abstract}

\section{Introdução}

A genética é o campo da biologia que estuda a natureza química do material hereditário, isto é, o mecanismo de transferência das informações contidas nos genes, compartilhados de geração em geração (dos pais para os filhos). $\mathrm{O}$ ensino desta disciplina, além de ser considerado complexo na visão de alguns alunos e professores, vem enfrentando dificuldades pela maneira como tem sido conduzido o ensino, através da memorização, da transmissão e recepção de conhecimentos, marcantes no ensino tradicional [AGAMME, 2010].

A grande quantidade de conceitos teóricos existentes nesta disciplina e a falta de uma metodologia voltada para o um aprendizado lúdico e motivador, dificulta a assimilação destes conceitos, levando os alunos a memorização e não ao aprendizado. Martins et al (2008) ressalta a necessidade de atividades práticas no ensino da genética que auxiliem no aprendizado dos alunos como complementação dos conceitos teóricos.

Entende-se que o processo de ensino e aprendizagem desta disciplina necessita de novas estratégias motivacionais, dinâmicas e atrativas. E isso pode ser resolvido através do uso de jogos educativos. Para Vieira et al (2005), a dificuldade em se ministrar aulas práticas, devido à falta de laboratórios e materiais em muitas escolas, tornam o jogo uma ferramenta importante do ensino e aprendizagem.

Diante disso, o uso de jogos educativos é de grande importância para ao processo de aprendizagem de biologia, pois na maioria das vezes, esses conteúdos são trabalhados de forma muito abstrata, sem qualquer correspondência com situações concretas [FERREIRA e PEREIRA, 2013]. Neste contexto, o presente artigo tem como objetivo apresentar o jogo educativo Leis de Mendel, voltado para o aprendizado lúdico e motivador da genética Mendeliana, este, tem como objetivo auxiliar o aluno durante assimilação de conceitos teóricos, de forma prática e interativa. O restante do artigo esta organizado da seguinte forma: a Seção 2 apresenta uma breve abordagem sobre jogos na educação; a Seção 3 apresenta método de desenvolvimento do jogo; a 
III Congresso Brasileiro de Informática na Educação (CBIE 2014)

XXV Simpósio Brasileiro de Informática na Educação (SBIE 2014)

Seção-4 descreve o jogo desenvolvido, destacando suas características e enredo e por fim, na Seção 5, são feitas as considerações sobre o tema abordado.

\section{Jogos na Educação}

A educação para o século XXI deve ser pensada para os estudantes do século XXI. Há de se considerar que começam a surgir trabalhos destinados ao aprendizado com games e que podem caracterizar-se de forma mais adequada para aprendizes na presente época. [FRANÇA, et al. 2013]

Além disso, a metodologia de ensino necessita evitar repetições didáticas, por mais verdadeira que possa ser, no intuito de obter um crescimento educacional, para isso se faz imprescindível que a ação didática seja mediada pelas necessidades dos alunos, por seus conhecimentos prévios e pelas intervenções que possam acontecer durante o planejamento do professor. [RAYS, 1988].

As emoções dos jogos têm como principal objetivo propiciar prazer. Desde o momento em que o jogador tem a oportunidade de descobrir e explorar as soluções diante do jogo, como também criar estratégias junto a outros jogadores, há um estímulo na resolução dos problemas enfrentados nos jogos. De acordo com Vigotsky (1988), “o jogo é um instrumento que medeia relações sociais de construção e potencializa a interação entre os sujeitos que, num processo coletivo, constroem a sua existência".

Os jogos eletrônicos proporcionam uma interação entre, aluno-aluno, aluno-professor e aluno-escola, além de ser uma ferramenta pedagógica, na qual professores e escolas podem utiliza-la agregando os conteúdos e disciplinas a serem trabalhados, desenvolvendo assim, o raciocínio e as habilidades cognitivas.

Existe atualmente a necessidade de uma preparação dos professores, para que os mesmos possam se adaptar as necessidades dos alunos, ao ambiente tecnológico, sendo mais interativo com o aluno, buscando diversos tipos de soluções dos problemas reais, porém algumas dificuldades são enfrentadas como, por exemplo, certa acomodação por parte de alguns professores que seguem sequências didáticas pré-determinadas ou propostas em livros.

Mais do que o domínio do computador, o que precisamos desenvolver em nossos alunos, são as habilidades mentais e pessoais, tais como a criatividade, iniciativa, espirito crítico, autoestima, colaboração, sociabilidade e a capacidade a partir das informações que recebe, selecionar as fontes fidedignas, e transforma-las em conhecimento. [OZORES et al FICHMANN, 1997].

Uma pesquisa sobre jogos relacionados foi feita e verificou-se que não há muitas produções, o que, de certa maneira, justifica a importância e a necessidade do presente trabalho. Segue abaixo, jogos relacionados ao Leis de Mendel:

Jardim de mendel, tem como proposta simular os experimentos realizados com ervilheiras pelo monge Mendel. Possui como roteiro apresentar o personagem principal e reproduzir de maneira sistemática os experimentos feitos pelo Mendel. [Barbaso, et al. 2013]. O jogo show de genética apresenta de forma dinâmica os conceitos em torno desta disciplina, é inspirado no programa "Show do Milhão", produzido pelo canal SBT, desta forma, diferentemente do jogo proposto neste artigo, a interação com o jogador baseia em perguntas e respostas. [Mastins, et al., 2010].

Oleira, et al (2010). Traz o jogo O Bingo das Ervilhas, é composto por duas cartelas principais com todos os Genótipos e Fenótipos, sendo uma para cada lei. Os genótipos devem ser 
III Congresso Brasileiro de Informática na Educação (CBIE 2014)

XXV Simpósio Brasileiro de Informática na Educação (SBIE 2014)

sorteados mantalmente pelo professer, a cada gene sorteado, os jogadores devem fazer os cruzamentos e marcar em sua cartela os fenótipos correspondentes com as figuras coloridas.

\section{Método de Desenvolvimento}

Para delimitação do projeto, utilizou-se o Project Model Canvas, criado pelo professor José Finocchio Jr., que utiliza conceitos de gerenciamento de projetos, neurociência e design thinking para simplificar a elaboração do Plano de Projeto [REIS, 2014].

$\mathrm{Na}$ fase inicial do projeto, optou-se pela pesquisa de campo, no intuito de apurar, as principais necessidades e dificuldades que envolvem o ensino da genética, baseando-se em duas visões: a visão do professor e a visão do aluno. Sendo assim, tomou-se como público alvo, alunos do $1^{\circ}$ ano do ensino médio e professores da disciplina de biologia, ambos de escolas públicas do município de Garanhuns/PE. Apurou-se na pesquisa de campo, que além da dificuldade de assimilação de conceitos teóricos, os livros didáticos não auxiliam muito, por não apresentar novas formas de exibir a informação e nem oferecer atividades que possam ser feitas de forma prática.

Percebeu-se assim, que um aplicativo no formato de jogo, fosse a solução mais adequada para o ensino da genética mendeliana, de forma a integrar o aprendizado com a diversão, criando laços interativos entre aluno-aluno e aluno-professor. O projeto foi composto por três alunos do curso de Licenciatura em Computação, da Universidade de Pernambuco - UPE - campus Garanhuns e apoiado por três professores da disciplina de Estágio III, tendo um deles como orientador. Baseado na metodologia de desenvolvimento ágil Scrum, o projeto de desenvolvimento foi dividido em quatro passos:

1 - Levantamento e aprendizagem dos conceitos de genética mendeliana: Nesta etapa pesquisou-se sobre o assunto no intuito de conhecer e aprender os conceitos da genética mendeliana.

2 - Design: Nesta etapa, foram desenvolvidos os protótipos do jogo. Levou-se em consideração critérios de Interação Humano Computador (IHC) e da Computação Gráfica, como: utilização de ícones, signos, textos e imagens representativas, de forma a facilitar a utilização do jogo pelo usuário.

3 - Desenvolvimento: Posteriormente aos passos 1 e 2, deu-se inicio ao processo de codificação. Utilizou-se o Game Maker Studio após pesquisa de viabilidade, que permitiu aplicar soluções que deixassem o jogo mais robusto.

4 - Teste: Integrado ao passo 3, a cada sprint (conjunto de atividades que deve ser executado) realizada, uma série de testes foram feitos, como teste de caixa branca, o qual trabalha diretamente com o código fonte e o teste de caixa preta o qual avalia o comportamento externo do componente de software, sem considerar o comportamento interno do mesmo.

\section{O jogo - Leis de Mendel}

O enredo do jogo conta a história de Mendel, monge que realizou uma série de experimentos com ervilhas, com o objetivo de entender como as características hereditárias eram transmitidas de pais para filhos [SÓ BIOLOGIA, 2014]. No jogo, Mendel é representado por um agente pedagógico estático, como pode ser observado na Figura 1. Visando uma maior aceitação por parte dos usuários, adotou-se critérios da computação afetiva para tornar o agente mais credível, tais como: diferentes expressões faciais e físicas que mudarão de acordo com situações vivenciados no jogo, fisionomia de um senhor alegre, óculos e vestimenta de monge. 
III Congresso Brasileiro de Informática na Educação (CBIE 2014)

XXV Simpósio Brasileiro de Informática na Educação (SBIE 2014)

Este agente interage com o usuário durante a introdução-dos-conceitos da Primeira e da Segunda Lei de Mendel. Diante desta interação, o jogador é estimulado a auxiliar o agente durante os experimentos com as ervilhas, de forma a interligar os conceitos com a prática no decorrer do processo de aprendizagem.

Após a introdução, o jogo assume o estilo de jogo puzzle ou "quebra-cabeça" (Figura 2), com diferentes estágios e níveis de complexidade crescente. Nos estágios da Primeira Lei, o tabuleiro tem a forma de uma matriz $4 \times 4$ e na Segunda Lei, por sua vez, uma matriz 8x8. As posições das ervilhas variam aleatoriamente cada vez que o jogo é iniciado. Para que o usuário associe os conceitos fenótipo e genótipo, além das cores (verde e amarela), os tipos e genes das ervilhas foram identificadas por letras. Para primeira lei utilizou-se as letras $\mathrm{P}$ e $\mathrm{H}$, correspondentes a pura e hibrida, respectivamente, na segunda lei, duas características são apresentadas, a cor e a textura, portanto utilizou-se 4 letras em cada ervilhas para identificar seus genes, que podem ser VV, Vv, vv (cor) e RR, Rr, rr (textura).

a)

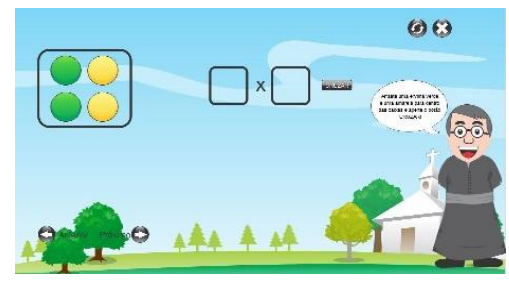

b)

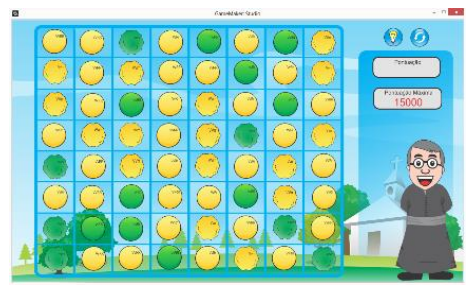

Figura 1. Telas do Jogo: a) Home; b) Tabuleiros da $1^{\text {a }}$ e $2^{\mathrm{a}}$ Leis de Mendel

Para conseguir passar de estágio, o jogador precisa realizar cruzamentos entre as ervilhas, para isso é necessário selecionar uma ervilha qualquer no tabuleiro e colidi-la com outra ervilha. A colisão só ocorrerá nas posições horizontal e vertical e ao serem colididas elas serão destruídas e em seu lugar surgirão as ervilhas resultantes do cruzamento. Para resolver os problemas de cada estágio, além dos conceitos aprendidos na introdução, o usuário é estimulado a utilizar e desenvolver suas habilidades cognitivas e raciocínio lógico para encontrar a melhor e mais rápida solução para o problema proposto.

O jogo proposto não trabalha com punições diante de erros, pois tem como principal objetivo que o usuário aprenda com tantas tentativas forem suficientes para passar dos estágios. Dessa forma, a cada cruzamento incorreto, o número de jogadas para atingir o objetivo será maior e, consequentemente, a pontuação será menor. O número de tentativas é infinito e sem limites de tempo. Ao concluir o objetivo do estágio, é verificada a pontuação que o usuário conseguiu, sendo assim sua premiação é dada como estrelas, a qual serve como motivação, além de permitir, caso alcance uma pontuação pré-determinada, que outras fases, do jogo, sejam desbloqueadas. $\mathrm{O}$ jogo Leis de Mendel, se enquadra no nível de aprendizagem criativo [Beineke, 2012], pois proporciona liberdade de escolha ao aluno, para que o mesmo possa achar a melhor solução para o problema que lhe é dado.

\section{Considerações Finais}

O presente trabalho apresentou o Leis de Mendel, jogo que visa apoiar o aprendizado da primeira e segunda Lei de Mendel. Desenvolvido para plataforma Windows, tem como contribuição uma proposta metodológica inovadora na área da biologia, por estimular o aprendizado através de desafios interativos, de forma que o usuário também desenvolva habilidades cognitivas ao utilizar o jogo.

Além dos conceitos, vários processos pedagógicos estão embutidos no jogo, processos estes que permite um crescimento na aprendizagem do aluno, como por exemplo, a 
III Congresso Brasileiro de Informática na Educação (CBIE 2014)

XXV Simpósio Brasileiro de Informática na Educação (SBIE 2014)

problematização que instiga 0 almno a pensar numa melhor selução para alcançar 0 -bjetivo da melhor forma possível.

Como trabalhos futuros, pretende-se validar os estágios já implementados, a partir de experimentos em turmas reais, visando identificar possíveis falhas que possam impactar de forma negativa durante a interação com o usuário, implementar novas funcionalidades, como por exemplo, tonar o jogo social, onde amigos verão a pontuações de outros e compilar o jogo para as plataformas móveis permitindo o acesso por diversos ambientes.

\section{Referências}

Agame, A. L. D. A. (2010). O lúdico no ensino de genética: a utilização de um jogo para entender a meiose. Disponível em: <http://www.mackenzie.br/fileadmin/Graduacao/CCBS/Cursos/Ciencias_Biologicas/1o_2012/ Biblioteca_TCC_Lic/2010/2o_2010/ANA_LUIZA_ABDO.pdf> Acesso em: 10/07/2014.

Barbosa, J. S. et al. (2013). O jardim de Mendel: um método lúdico para o ensino da genética. In IX Congresso de iniciação científica do IFRN.

Beineke, V. (2012). Aprendizagem criativa e educação musical: trajetórias de pesquisa e perspectivas educacionais. In Educação, Santa Maria, v. 37, n. 1, p. 45-60, jan./abr.

França, S. R; Silva, C. W; Amaral, C. J. H. (2013). Computino: um jogo destinado à aprendizagem de Números Binários para estudantes da educação básica. In XXI Workshop sobre Educação em Computação (WEI) - XXXIII Congresso da Sociedade Brasileira de Computação.

Ferreira, G. R. A. M; Pereira, S. L. P. O. (2013). Jogos digitais no ensino formal em escolas da rede pública: possibilidades e interações. In SimSocial, Salvador-BA.

Martins, C. et al. (2008). Show da genética: um jogo interativo para o ensino de genética. In Sociedade Brasileira de Genética (SBG) - Revista Genética na escola, vol. III, nº2, p. 24.

Oleira, et al (2010). Cruzamentos mendelianos: o bingo das ervilhas. In Sociedade Brasileira de Genética (SBG) - Revista Genética na escola, vol. V, nº1, p. 5.

Ozores, E. P.; Fichmann, S. Informática na educação. In: TIBURCIO, C. Guia de informática e internet para educação brasileira. São Paulo: T \& M, 1997.

Reis, T. (2014). A Diferença entre o Plano de Projeto e o Project Model Canvas. Disponível em <http://www.projectbuilder.com.br/blog-pb/entry/blog-gestao-de-projetos/a-diferenca-entre-oplano-de-projeto-e-o-project-model-canvas>. Acesso em: 01 de Jul de 2014.

Rays, O. A. A. (1988) questão da metodologia do ensino na didática escolar. In: VEIGA, lima Passos Alencastro da (org.). Repensando a didática. Campinas. p. 83.

Só Bilogia. "Mendel, o iniciador da genética" Disponível em <http://www.sobiologia.com.br/conteudos/Genetica/leismendel.php> Acesso em: 5 de Jul. 2014.

VIGOTSKY, L.S. Pensamento e linguagem. São Paulo: Martins Fontes, 1984. 